\title{
Antiangiogenic effects of oxymatrine on pancreatic cancer by inhibition of the NF-кB-mediated VEGF signaling pathway
}

\author{
HUI CHEN $^{1 *}$, JIANHONG ZHANG $^{1 *}$, JIANG LUO $^{1 *}$, FUJI LAI $^{1}$, ZHAOHONG WANG $^{1}$, \\ HONGFEI TONG ${ }^{1}$, DIAN LU ${ }^{1}$, HEQI BU ${ }^{1}$, RIYUAN ZHANG ${ }^{1}$ and SHENGZHANG LIN ${ }^{1,2}$ \\ ${ }^{1}$ Department of Hepatobiliary-Pancreatic Surgery, The Second Affiliated Hospital of Wenzhou Medical College, \\ Wenzhou, Zhejiang 325027; ${ }^{2}$ Department of Hepatobiliary-Pancreatic Surgery, The First Affiliated Hospital, \\ Zhejiang University School of Medicine, Hangzhou, Zhejiang 310003, P.R. China
}

Received March 14, 2013; Accepted April 29, 2013

DOI: $10.3892 /$ or.2013.2529

\begin{abstract}
Oxymatrine, the main alkaloid component in the traditional Chinese herbal medicine Sophora japonica (Sophora flavescens Ait), has been reported to have antitumor properties. However, the mechanisms of action in human pancreatic cancer are not well established to date. In the present study, we investigated the antiangiogenic effects of oxymatrine on human pancreatic cancer as well as the possible mechanisms involved. The results of the cell viability assay showed that treatment of PANC-1 pancreatic cancer cells with oxymatrine resulted in cell growth inhibition in a dose- and time-dependent manner. To investigate the possible mechanisms involved in these events, we performed western blotting and reverse transcription-polymerase chain reaction (RT-PCR) analysis. The results revealed that oxymatrine decreased the expression of angiogenesis-associated factors, including nuclear factor $\kappa \mathrm{B}(\mathrm{NF}-\kappa \mathrm{B})$ and vascular endothelial growth factor (VEGF). Finally, the antiproliferative and antiangiogenic effects of oxymatrine on human pancreatic cancer were further confirmed in pancreatic cancer xenograft tumors in nude mice. In conclusion, our studies for the first time suggest that oxymatrine has potential antitumor effects on pancreatic cancer via suppression of angiogenesis, probably through regulation of the expression of the NF- $\kappa \mathrm{B}$-mediated VEGF signaling pathway.
\end{abstract}

\section{Introduction}

Pancreatic cancer is the most lethal of solid tumors and is the fourth leading cause of cancer-related mortality in the

Correspondence to: Professor Shengzhang Lin, The Second Affiliated Hospital of Wenzhou Medical College, No. 109 West Xueyuan Road, Wenzhou, Zhejiang 325027, P.R. China

E-mail: wzf21sz@163.com

${ }^{*}$ Contributed equally

Key words: antiangiogenesis, oxymatrine, nuclear factor $\kappa \mathrm{B}$, vascular endothelial growth factor
USA (1). At present, surgical resection offers the only chance of a cure (2). Unfortunately, 80-85\% of patients present with advanced unresectable disease (2). Many patients with locally advanced or metastatic pancreatic cancer rely on gemcitabine chemotherapy (3). However, pancreatic cancer is representative of the most highly vascularized and angiogenic solid tumors, which responds poorly to most chemotherapeutic agents $(2,3)$. Therefore, the poor prognosis of pancreatic cancer is related to angiogenesis. Thus, identification of new treatment strategies possessing antiangiogenic capability is urgently needed in clinical practice in order to inhibit the metastasis of pancreatic cancer and improve its prognosis.

Traditional Chinese medicine has held an important position in primary health care in China and has been recognized by Western countries as a fertile source for revealing novel lead molecules for modern drug discovery (4). Various active components of traditional Chinese herbs have been reported to exhibit antiproliferative effects on cancer cells and serve as potent agents to enhance the therapeutic effects of chemotherapy in human cancers (4-6). Oxymatrine is one of the main alkaloid components in the traditional Chinese herbal medicine Sophora japonica (Sophora flavescens Ait). It is commonly known to have specific pharmacological properties for anti-hepatic fibrosis, anti-inflammation and against hepatitis $\mathrm{B}$ viruses $(7,8)$. Oxymatrine also has been found to exhibit antitumor effects including induction of apoptosis and cell cycle arrest (9-11), downregulation of the activity of the Wnt/ $\beta$-catenin signaling pathway (12), upregulation of p53 $(13,14)$ and suppression of xenografted SGC-7901 human gastric cancer cell growth in vivo (14). However, the mechanisms of the antitumor properties of oxymatrine in human pancreatic cancer are not well established to date.

Nuclear factor $\kappa \mathrm{B}(\mathrm{NF}-\kappa \mathrm{B})$ activation has been connected with multiple aspects of tumor development and progression, including the control of apoptosis, the cell cycle, differentiation and cell migration $(15,16)$. Accumulating evidence suggests that NF- $\kappa \mathrm{B}$ transcriptional factors are constitutively activated in the majority of pancreatic cancers (17). It has been reported that constitutive activation of $N F-\kappa B$ can regulate the expression of genes associated with angiogenesis (18). Notably, one study also reported the antitumor activity of oxymatrine against tumor cells by inhibition of NF- $\kappa \mathrm{B}$ activation (19). In 
the present study, we aimed to investigate whether oxymatrine inhibits the angiogenesis of pancreatic cancer through a possible mechanism involving $\mathrm{NF}-\kappa \mathrm{B}$. We found that treatment with oxymatrine inhibited the growth of pancreatic cancer PANC-1 cells and decreased the expression of angiogenesisassociated factors, including $\mathrm{NF}-\kappa \mathrm{B}$ and vascular endothelial growth factor (VEGF). We further demonstrated the tumor growth inhibition and antiangiogenic effects of oxymatrine on pancreatic cancer in vivo.

\section{Materials and methods}

Reagents and antibodies. Oxymatrine and dimethyl sulfoxide (DMSO) were obtained from Sigma-Aldrich (St. Louis, MO, USA). Dulbecco's modified Eagle's medium (DMEM), fetal bovine serum (FBS), penicillin-streptomycin, trypsin-EDTA were obtained from Gibco-BRL (Invitrogen Life Technologies, Grand Island, NY, USA). Antibodies were obtained from the following commercial sources: rabbit NF- $\kappa \mathrm{B}$ p65 and VEGF antibody (Abcam, Cambridge, UK); rabbit vascular endothelial growth factor receptor-2 (VEGFR-2) antibody (Santa Cruz Biotechnology, Inc., Santa Cruz, CA, USA); rabbit $\beta$-tubulin antibody (Cell Signaling Technology, Inc., Beverly, MA, USA); and horseradish peroxidase (HRP)-conjugated goat anti-rabbit secondary antibody (Beyotime Biotechnology, Haimen, China). The ultrasound contrast agent SonoVue was obtained from Bracco (Switzerland). The contrast agent was dissolved in $5 \mathrm{ml} 0.9 \%$ sodium chloride solution and the final concentration was $45 \mu \mathrm{g} / \mathrm{ml}$.

Cell line and culture. The human pancreatic cancer cell line PANC-1 was purchased from the Shanghai Cell Bank (Shanghai, China). Cells were cultured in DMEM with $10 \%$ FBS, 100 units $/ \mathrm{ml}$ penicillin and $100 \mu \mathrm{g} / \mathrm{ml}$ streptomycin at $37^{\circ} \mathrm{C}$ under a humidified $5 \% \mathrm{CO}_{2}$ atmosphere. The medium was replaced every 2-3 days, and the cells were subcultured when confluency reached $70-80 \%$ by $0.25 \%$ trypsin-EDTA at $37^{\circ} \mathrm{C}$.

Cell viability assay. The Cell Counting Kit-8 (CCK-8) (Dojindo Molecular Technologies, Kunamoto, Japan) was used to assess the viability of cells after oxymatrine treatment. PANC-1 cells were seeded into 96 -well plates at a density of $\sim 5 \times 10^{3}$ cells/ well and grown for $24 \mathrm{~h}$. Cells were treated with $0.25,0.5,1$, 2, 4 and $6 \mathrm{mg} / \mathrm{ml}$ oxymatrine or DMSO (control) for 12, 24 or $36 \mathrm{~h}$, and then $10 \mu \mathrm{l}$ CCK-8 reagent was added to $100 \mu \mathrm{l}$ of media in each well, and the incubation was continued for a further $3 \mathrm{~h}$. The absorbance (A) of each well was determined with an enzyme-linked immunosorbant assay (ELISA) reader (ELx808; Bio-Tek Instruments, Inc., Winooski, VT, USA) at a wavelength of $450 \mathrm{~nm}$. The percentage of cell viability was calculated using the following equation: Cell viability $(\%)=\left(\mathrm{A}_{\text {sample }}-\mathrm{A}_{\text {blank }}\right) /\left(\mathrm{A}_{\text {control }}-\mathrm{A}_{\text {blank }}\right) \times 100 \%$.

Protein extraction and western blot analysis. Approximately $5 \times 10^{5}$ PANC-1 cells/well were seeded into 6 -well plates, allowed to adhere overnight, and treated with $0.5,1,2 \mathrm{mg} / \mathrm{ml}$ oxymatrine or DMSO (control) respectively for $24 \mathrm{~h}$. Treated cells were collected and total proteins were extracted using cell lysis buffer $(20 \mathrm{mmol} / \mathrm{l}$ Tris- $\mathrm{HCl} \mathrm{pH} 7.5,150 \mathrm{mmol} / \mathrm{l} \mathrm{NaCl}$,
$1 \mathrm{mmol} / 1 \mathrm{Na}_{2}$ EDTA, $1 \mathrm{mmol} / 1$ EGTA, 1\% Triton, $2.5 \mathrm{mmol} / 1$ sodium pyrophosphate, $1 \mathrm{mmol} / 1 \beta$-glycerophosphate, $1 \mathrm{mmol} / 1 \mathrm{Na}_{3} \mathrm{VO}_{4}, 1 \mu \mathrm{g} / \mathrm{ml}$ leupeptin, $1 \mathrm{mmol} / 1 \mathrm{PMSF}$; Cell Signaling Technology, Inc.). After centrifugation at 14,000 x g for $15 \mathrm{~min}$ at $4^{\circ} \mathrm{C}$, the supernatant was collected and the protein concentration was detected using the BCA Protein Assay kit (Pierce Biotechnology, Inc., Rockford, IL, USA), according to the manufacturer's instructions. Equal amounts of protein were separated on 8-12\% SDS-PAGE and transferred onto a polyvinylidene difluoride membrane (Millipore, Billerica, MA, USA). After blocking with 5\% nonfat milk in TBST washing buffer, the membrane was incubated with the specific primary antibodies at $4^{\circ} \mathrm{C}$ overnight. After being washed at room temperature with washing buffer, the blots were labeled with peroxidase-conjugated secondary antibodies. The formed immunocomplex was visualized using an enhanced chemiluminescence kit (Pierce Biotechnology, Inc.) according to the manufacturer's instructions and exposed to X-ray film.

Reverse transcription-polymerase chain reaction (RT-PCR) analysis. PANC-1 cells were seeded into 6-well plates at a density of $\sim 5 \times 10^{5}$ cells/well and grown for $24 \mathrm{~h}$. Cells were treated with $0.5,1,2 \mathrm{mg} / \mathrm{ml}$ oxymatrine or DMSO (control) respectively for $24 \mathrm{~h}$. Total RNA was isolated from the treated cells using the TRIzol reagent (Invitrogen Life Technologies). For reverse transcription (RT) analysis, $1 \mu \mathrm{g}$ of total RNA was reverse transcribed in a $20-\mu 1$ volume, using the RevertAid ${ }^{\mathrm{TM}}$ First Strand cDNA Synthesis kit (Fermentas, St. Leon-Rot, Germany). One microliter of the RT reaction mixture was then PCR-amplified in a PCR machine (Eppendorf, Hamburg, Germany). The PCR profile was as follows: $5 \mathrm{~min}$ at $94^{\circ} \mathrm{C}$ followed by 35 cycles of $30 \mathrm{sec}$ at $94^{\circ} \mathrm{C}, 30 \mathrm{sec}$ at $54^{\circ} \mathrm{C}, 30 \mathrm{sec}$ at $72^{\circ} \mathrm{C}$; the final cycle was modified to allow for a 5 -min extension at $72^{\circ} \mathrm{C}$. The PCR primers were as follows: NF- $\kappa \mathrm{B}$ (300 bp) sense, 5'-AGCACAGATACCACCAAGACCC-3' and antisense, 5'-CCCACGCTGCTCTTCTATAGGAAC-3'; VEGF (336 bp) sense, 5'-TGCCCACTGAGGAGTCCAAC-3' and antisense, 5'-TGGTTCCCGAAACGCTGAG-3'; glyceraldehyde-3-phosphate dehydrogenase (GAPDH) (533 bp) sense, 5'-CGGAGTCAACGGATTTGGCC-3' and antisense, 5'-GTGCAGAGATGGCATGGAC-3'. Sequences of the primers were designed using the software Primer Premier 5. GAPDH was used for quantification of the samples. PCR products were electrophoresed at $120 \mathrm{~V}$ for $45 \mathrm{~min}$ on a $1.2 \%$ agarose gel and imaged. The grey value was analyzed using Quantity One version 4.5 software (Bio-Rad, Hercules, CA, USA).

Animals and in vivo studies. BALB/C (nu/nu), 4 week-old, male mice were purchased from Shanghai Laboratory Animal Center (Shanghai, China) and maintained under specific pathogen-free conditions. Mice were allowed to acclimate for 1 week before the start of the experiments. All animal studies performed in this study were reviewed and approved by the Animal Research and Ethics Committee of Wenzhou Medical College. The orthotopic pancreatic cancer xenograft tumor model was established as described by us previously (20). The dose of oxymatrine was determined by balancing the antitumor and side effects on the basis of previous trials. Through numerous trials, we found that oxymatrine at a dose of $100 \mathrm{mg} / \mathrm{kg}$ body weight by intraperitoneal injection 
3 days/week can effectively inhibit tumor growth without significant side effects, such as noticeable weight loss and decrease in overall activity. Therefore, oxymatrine treatment $(100 \mathrm{mg} / \mathrm{kg}$ body weight) by intraperitoneal injection 3 days/week was administered in this study. Briefly, nude mice were anesthetized with pentobarbital sodium, a small left abdominal flank incision was made, and PANC- 1 cells $\left(5 \times 10^{6}\right)$ in $50 \mu \mathrm{l}$ serum-free media were injected into the subcapsular region of the pancreas. All surgical procedures were conducted under sterilized conditions. One week after cell implantation, a total of 32 nude mice were randomized into 2 groups (control and oxymatrine group) with 16 mice/group. The control group mice were treated with $0.9 \%$ sodium chloride and the treatment was continued for 4 weeks.

After the first treatment, 8 mice in each group were used for a survival study which was carried out up to 60 days. When mice died during the period of the survival study, the number of living days were recorded. At the end of the survival study, the living mice were sacrificed. One week after the last treatment, the other 8 mice in each group were used for the study of tumor blood flow detected by contrast enhanced ultrasonography (CEUS). Then the mice were sacrificed, and the tumors were removed. The tumors were weighed with an electronic balance, and tumor volumes were calculated with a vernier caliper according to the following formula: Volume $=(4 \pi / 3)$ $\mathrm{x}(\text { width } / 2)^{2} \mathrm{x}($ length/2).

CEUS for detecting tumor blood flow. One week after the last treatment, the mice were used for the study of tumor blood flow as detected by CEUS. Mice were anesthetized with sodium pentobarbital $(50 \mathrm{mg} / \mathrm{kg})$ and pronely positioned on an operating table. Mice were injected with $20 \mu \mathrm{l}$ ultrasound SonoVue and $200 \mu 10.9 \%$ sodium chloride solution per mouse via the tail vein and then imaged. A 1-min data collection was performed after the contrast agent injection. The images were analyzed with the ultrasound contrast analysis software that accompanies the ultrasonic imaging system (Siemens S2000, Germany). A parameter, peak intensity (PI), is in direct proportion to blood flow and was used here for quantification of the tumor blood perfusion in the pancreatic cancer xenografts.

Statistical analysis. Data are represented as means \pm SD for the absolute values or percent of controls. SPSS13.0 software was used for statistical analysis. Differences between the oxymatrine-treated and DMSO-treated (control) groups were analyzed by the unpaired Student's t-test or ANOVA analysis. A value of $\mathrm{P}<0.05$ was considered to indicate a statistically significant result.

\section{Results}

Oxymatrine inhibited the viability of human pancreatic cancer PANC-1 cells. The viability of human pancreatic cancer PANC-1 cells were measured by CCK- 8 assay. As shown in Fig. 1, oxymatrine inhibited the cell viability in a dose- and time-dependent manner. Notably, the cell viability was drastically decreased at the range of concentrations of $0.5-2 \mathrm{mg} / \mathrm{ml}$ of oxymatrine. However, at concentrations of $0.25-0.5 \mathrm{mg} / \mathrm{ml}$ oxymatrine, the cell viability was minimally altered, and higher concentrations of oxymatrine $(>2 \mathrm{mg} / \mathrm{ml})$

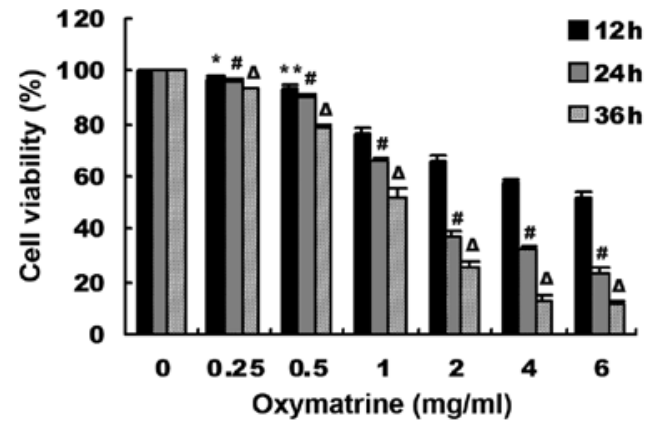

Figure 1. Effects of oxymatrine on the viability of pancreatic cancer PANC-1 cells. Oxymatrine inhibited the cell viability in a dose- and time-dependent manner. PANC-1 cells were incubated with $0.25,0.5,1,2,4$ and $6 \mathrm{mg} / \mathrm{ml}$ oxymatrine or dimethyl sulfoxide (DMSO) (control) for 12, 24 or $36 \mathrm{~h}$ and cell viability was measured by CCK- 8 assay with 6 replicates per concentration of oxymatrine. Data were obtained from 3 separate experiments and are expressed as means \pm SD. ${ }^{*} \mathrm{P}<0.05,{ }^{* *} \mathrm{P}<0.01,{ }^{\#} \mathrm{P}<0.01$ and ${ }^{\Delta} \mathrm{P}<0.01$ compared with DMSO-treated cells at the indicated time points.

had a saturated inhibitory effect. Therefore, we chose the concentrations of $0.5,1$ and $2 \mathrm{mg} / \mathrm{ml}$ for the following in vitro studies. Meanwhile, we chose one time point $(24 \mathrm{~h})$ for the further studies.

Effects of oxymatrine on the expression of $N F-\kappa B$ in PANC-1 cells. We investigated whether NF- $\kappa \mathrm{B}$ is involved in the antiproliferative effects of oxymatrine on pancreatic cancer PANC-1 cells. As shown in Fig. 2A, a dose-dependent decrease in NF- $\mathrm{kB}$ p65 expression as determined by western blot assay was observed after the cells were exposed to increasing concentrations of oxymatrine. The mRNA levels of NF- $\kappa B$ as detected by RT-PCR analysis was significantly decreased when compared with that in the control group (Fig. 2B, $\mathrm{P}<0.01$ ).

Effects of oxymatrine on the expression of VEGF and VEGFR-2 in PANC-1 cells. Our data showed that the protein (Fig. 3A) and mRNA (Fig. 3B) expression levels of VEGF were significantly decreased after PANC-1 cells were treated with 1 or $2 \mathrm{mg} / \mathrm{ml}$ oxymatrine for $24 \mathrm{~h}$. However, obvious inhibitory effects on VEGF by oxymatrine were not observed in the $0.5 \mathrm{mg} / \mathrm{ml}$ oxymatrine group. Moreover, we found that oxymatrine did not regulate the expression of VEGFR-2 (a receptor of VEGF) as determined by western blot assay in the PANC-1 cells (Fig. 3A).

Antiproliferative effects of oxymatrine on pancreatic cancer xenograft tumors in nude mice. To further confirm the antiproliferative effects of oxymatrine on pancreatic cancer, we established orthotopic pancreatic cancer xenograft tumors in nude mice. One week after the last oxymatrine treatment, the mice were sacrificed and tumors were removed (Fig. 4A). The weight of the tumors in the vehicle-treated mice was 1.54 -fold higher than that of the oxymatrine-treated mice $(\mathrm{P}<0.01$, Fig. 4B). Tumor volumes in the oxymatrine-treated mice and vehicle-treated mice were $438.23 \pm 123.40$ and $702.73 \pm 101.00 \mathrm{~mm}^{3}$, respectively $(\mathrm{P}<0.01$, Fig. $4 \mathrm{C})$. The median survival time of mice in the oxymatrine group (58 days) was significantly longer than that in the control group (40 days) (Fig. 4D). 
A
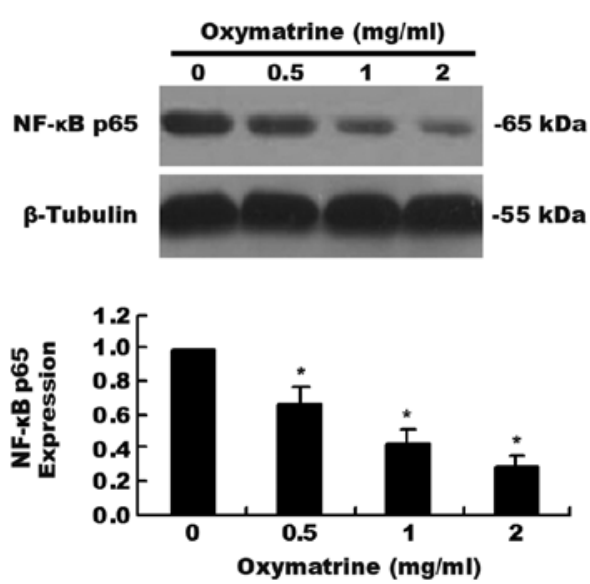

B
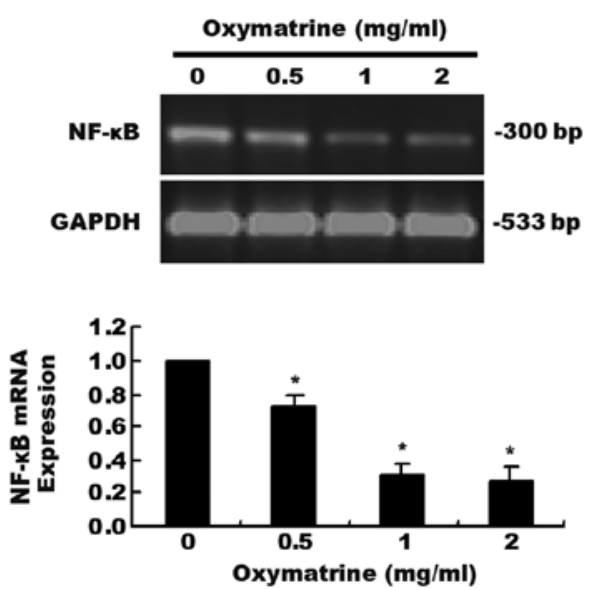

Figure 2. Effects of oxymatrine on the expression of NF- $\kappa \mathrm{B}$ in PANC-1 cells. PANC-1 cells were treated with $0.5,1,2 \mathrm{mg} / \mathrm{ml}$ oxymatrine or dimethyl sulfoxide (DMSO) (control) respectively for $24 \mathrm{~h}$. Western blot and RT-PCR were performed. (A) Western blot analysis for NF- $\mathrm{KB}$ p65. The relative protein expression of NF- $\mathrm{\kappa B}$ p 65 was represented by the ratio of the density of $\mathrm{NF}-\mathrm{kB}$ p65 to $\beta$-tubulin. The results obtained from 3 separate experiments are expressed as means $\pm \mathrm{SD} ;{ }^{*} \mathrm{P}<0.01$ compared with the DMSO-treated cells. (B) NF- $\kappa \mathrm{B}$ mRNA expression as detected by RT-PCR. The relative mRNA expression of NF- $\kappa B$ was represented by the ratio of the density of $\mathrm{NF}-\kappa \mathrm{B}$ to GAPDH. The results obtained from 3 separate experiments are expressed as means $\pm \mathrm{SD} ;{ }^{*} \mathrm{P}<0.01$ compared with the DMSO-treated cells.

Antiangiogenic effects of oxymatrine on pancreatic cancer xenograft tumors in nude mice. To further confirm the role of oxymatrine in the inhibition of tumor angiogenesis in pancreatic cancer, CEUS was employed to detect the tumor blood flow in pancreatic cancer xenograft mouse tumors 1 week after the last oxymatrine treatment (Fig. 5A). As shown in Fig. 5B, oxymatrine treatment markedly reduced the PI value, the data was $15.93 \pm 2.77$ (oxymatrine group) to $22.87 \pm 2.56$ (control group) $(\mathrm{P}<0.05)$.

\section{Discussion}

Pancreatic cancer is a highly malignant tumor in the alimentary system and is associated with a poor prognosis. It can only be managed with surgical resection in limited cases, whereas the majority of cases presenting with advanced tumors respond poorly to currently available medical therapies (21). In this study, the viability of human pancreatic cancer
A
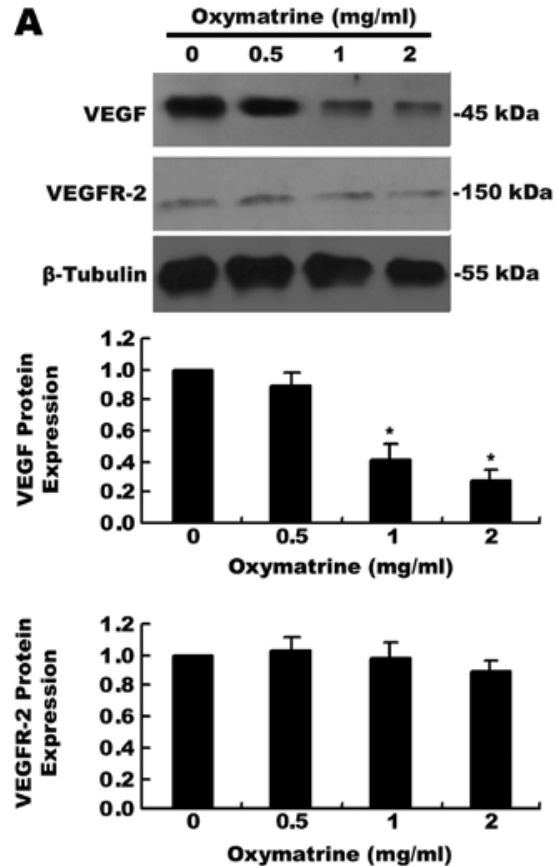

B
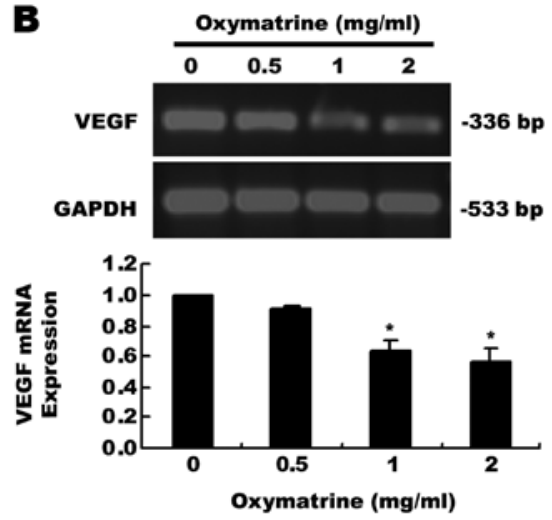

Figure 3. Effects of oxymatrine on the expression of vascular endothelial growth factor (VEGF) and vascular endothelial growth factor receptor-2 (VEGFR-2) in PANC-1 cells. PANC-1 cells were treated with $0.5,1,2 \mathrm{mg} / \mathrm{ml}$ oxymatrine or dimethyl sulfoxide (DMSO) (control) respectively for $24 \mathrm{~h}$. Western blotting and RT-PCR were performed. (A) Western blot analysis for VEGF and VEGFR-2. The relative protein expression of VEGF and VEGFR-2 was represented by the ratio of the density of VEGF to $\beta$-tubulin, VEGFR-2 to $\beta$-tubulin, respectively. The results obtained from 3 separate experiments are expressed as means $\pm \mathrm{SD} ;{ }^{*} \mathrm{P}<0.01$ compared with the DMSO-treated cells. (B) VEGF mRNA expression as detected by RT-PCR. The relative mRNA expression of VEGF was represented by the ratio of the density of VEGF to GAPDH. The results obtained from 3 separate experiments are expressed as means $\pm \mathrm{SD} ;{ }^{*} \mathrm{P}<0.01$ compared with the DMSO-treated cells

PANC-1 cells was largely inhibited by oxymatrine through an $\mathrm{NF}-\mathrm{kB}$-mediated mechanism. In vivo studies, we found that oxymatrine effectively inhibited the tumor growth and angiogenesis in the pancreatic cancer xenograft mice tumors.

It was reported that NF- $\mathrm{KB}$ is constitutively active in 9 of 11 pancreatic cancer cell lines (22), but not in immortalized, non-tumorigenic pancreatic ductal epithelial cells (23). It was also found to play a crucial role in predicting the efficacy of cetuximab and irinotecan in advanced colorectal tumors (24). Therefore, these findings suggest that NF- $\mathrm{BB}$ plays a major role in the growth and chemoresistance of pancreatic cancer, and blocking NF- $\mathrm{KB}$ activation could exert a growth inhibition 
A

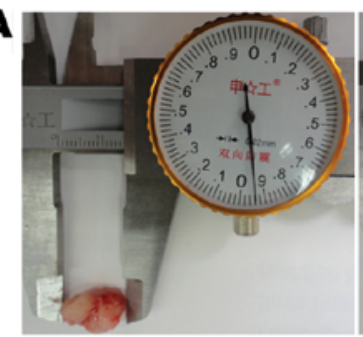

Control

C

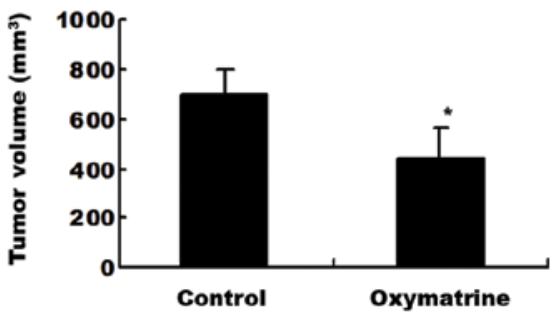

$\mathbf{B}$
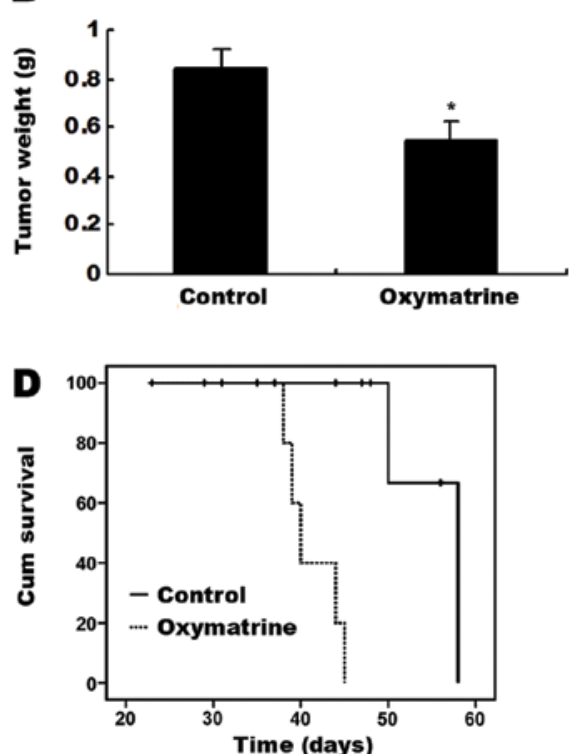

Figure 4. Effects of oxymatrine on the tumor weight, volume and the survival time of pancreatic cancer xenograft tumor mice. (A) Images of excised pancreatic tumors. One week after the last treatment, tumors were excised from the mice and tumor volumes and weights were measured. (B) Tumor weights. The tumors were weighed with an electronic balance. Data are expressed as means $\pm \mathrm{SD} ;{ }^{*} \mathrm{P}<0.01$ compared with the control group. (C) Tumor volumes. Tumor volumes were calculated with a vernier caliper. Data are expressed as means $\pm \mathrm{SD} ;{ }^{*} \mathrm{P}<0.01$ compared with the control group. (D) The survival time of pancreatic cancer xenograft tumor mice. Kaplan-Meier curves indicate the survival for mice treated with sodium chloride (control) and oxymatrine.
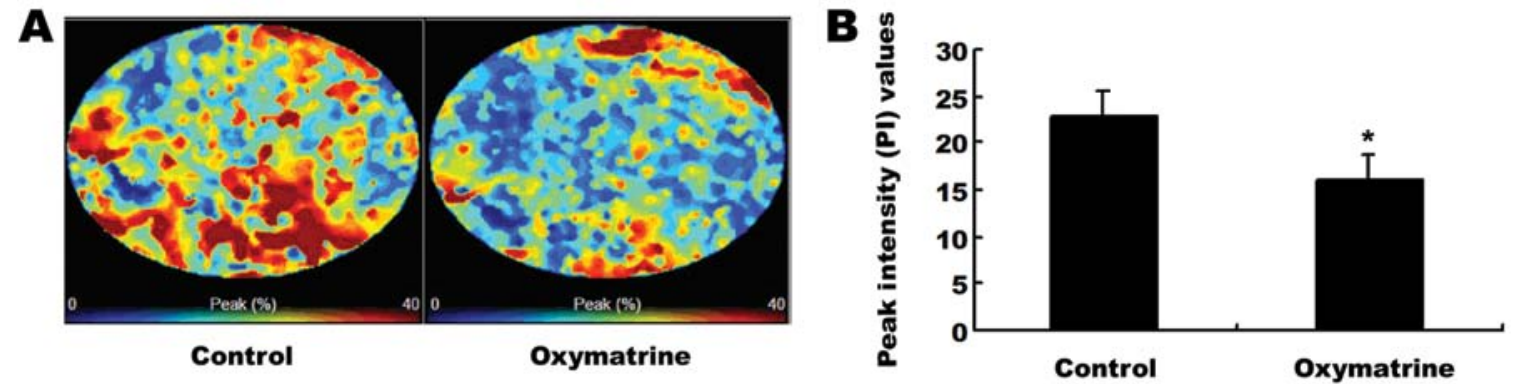

Figure 5. Effects of oxymatrine on the tumor blood flow of pancreatic cancer xenograft tumors. (A) Contrast enhanced ultrasonography (CEUS) imaging. One week after the last oxymatrine treatment, the mice in each group were used for the study of tumor blood flow detected by CEUS. The region of interest (ROI) indicated the entire transplanted tumor and peak intensity (PI) was obtained. The PI value is in direct proportion to tumor blood flow. (B) PI values. The of $\mathrm{PI}$ values are expressed as means $\pm \mathrm{SD}$; ${ }^{*} \mathrm{P}<0.05$ compared with the control group.

effect on pancreatic cancer. Presently, there are 5 known members of the NF- $\mathrm{B}$ family: p50/p105, p52/p100, p65, c-Rel, and RelB, and the NF- $\mathrm{BB}$ complex is sequestered as an inactive form in the cytoplasm by inhibitory IkB protein $(15,25)$. Upon stimulation, IkB is rapidly phosphorylated and degraded via the ubiquitin proteosome pathway resulting in the liberation of $\mathrm{NF}-\kappa \mathrm{B}$, allowing $\mathrm{NF}-\kappa \mathrm{B}$ members to accumulate in the nucleus $(15,25)$. Moreover, Han et al (19) reported that oxymatrine exerted antitumoral activity in H460 and Eca-109 tumor cells via inhibition of $\mathrm{NF}-\kappa \mathrm{B}$ activation. In the present study, the result of western blot analysis showed that oxymatrine decreased the levels of NF- $\kappa \mathrm{B}$ p65 in PANC-1 cells, and $\mathrm{NF}-\kappa \mathrm{B}$ mRNA levels detected by RT-PCR were downregulated in oxymatrine-treated cells. These findings suggest that inhibition of NF- $\mathrm{BB}$ is involved in the antiproliferative activity of oxymatrine in pancreatic cancer.

Angiogenesis, is critical for normal and pathologic processes and plays an important role in the growth and spread of cancer. Upon formation of new blood vessels, cancer cells acquire more oxygen and nutrients and invade nearby tissues, resulting in the spread to other parts of the body. Previous studies have suggested that $\mathrm{NF}-\kappa \mathrm{B}$ regulates the expression of several angiogenesis-associated molecules such as VEGF, MMP-2, MMP-9 and eNOS (26-28). Accumulating evidence had established the fundamental role of VEGF as a key regulator of normal and abnormal angiogenesis $(29,30)$. VEGF strongly stimulates endothelial migration and proliferation and the formation of new blood vessels. VEGF withdrawal has been shown to result in regression of vasculature in several physiological and pathological circumstances (30). In the present in vitro studies, the results of western blotting and RT-PCR suggest that oxymatrine diminishes the expression of VEGF and thus suppresses tumor angiogenesis. However, expression of VEGFR-2 (one receptor of VEGF) shown by western blotting was minimally decreased after oxymatrine treatment in PANC-1 cells, indicating that the inhibition of 
angiogenesis by oxymatrine in pancreatic cancer is not associated with the VEGF receptor.

To further confirm the role of oxymatrine in inhibition of tumor growth and angiogenesis in pancreatic cancer, we established orthotopic pancreatic cancer xenograft tumors in nude mice. Our studies showed that oxymatrine effectively inhibited tumor growth, and the median survival time of mice in the oxymatrine-treated group was markedly longer than that in the control group, which suggested that oxymatrine significantly improves the survival time of mice bearing pancreatic cancer xenograft tumors. The growth and metastasis of tumors are dependent on new blood vessel formation, and the microvessel density is often used as a quantified factor of tumor vasculature (31). It has been reported that detection of microvessel density does not provide precise information concerning antiangiogenic therapy (32). CEUS is a new diagnostic tool to evaluate the early effects of antiangiogenic treatment and is being increasingly employed in the clinic $(33,34)$. In this study, we employed CEUS to detect tumor blood flow in pancreatic cancer xenograft mouse tumors aftrer oxymatrine treatment. The results of CEUS showed that oxymatrine markedly reduced PI values of tumors and thus inhibited the angiogenesis of pancreatic cancer. The in vivo studies further confirmed the antiangiogenic effects of oxymatrine on human pancreatic cancer.

In the present study, we demonstrated the antiproliferative and antiangiogenic effects of oxymatrine on pancreatic cancer in vitro and in vivo. These results suggest that the $\mathrm{NF}-\kappa \mathrm{B}$ pathway plays an important role in oxymatrine-induced VEGF signaling inhibition and antiangiogenesis in pancreatic cancer. Moreover, targeting the NF- $\mathrm{KB}$ and VEGF pathway may reveal potential therapeutic options for pancreatic cancer, and oxymatrine may be a promising antiangiogenic strategy for pancreatic cancer.

\section{Acknowledgements}

The authors thank the entire staff of the Animal Experimental Center in the scientific research platform of the Second Affiliated Hospital of Wenzhou Medical College and the Animal Experimental Center of Zhejiang University School of Medicine for the helpful assistance. The authors are grateful for the funding from the Zhejiang Provincial Science Fund for Distinguished Young Scholars (grant no. LR12H280001) and the National Natural Science Foundation of China (grant no. 81173606) and Wenzhou Science and Technology Projects (grant no. Y20110037).

\section{References}

1. Raimondi S, Maisonneuve P and Lowenfels AB: Epidemiology of pancreatic cancer: an overview. Nat Rev Gastroenterol Hepatol 6: 699-708, 2009.

2. Vincent A, Herman J, Schulick R, Hruban RH and Goggins M: Pancreatic cancer. Lancet 378: 607-620, 2011.

3. Stathis A and Moore MJ: Advanced pancreatic carcinoma: current treatment and future challenges. Nat Rev Clin Oncol 7: 163-172, 2010.

4. Li-Weber M: Targeting apoptosis pathways in cancer by Chinese medicine. Cancer Lett 332: 304-312, 2013.

5. Lin SZ, Wei WT, Chen H, et al: Antitumor activity of emodin against pancreatic cancer depends on its dual role: promotion of apoptosis and suppression of angiogenesis. PLoS One 7: e42146, 2012.
6. Wei WT, Chen H, Ni ZL, et al: Antitumor and apoptosis-promoting properties of emodin, an anthraquinone derivative from Rheum officinale Baill, against pancreatic cancer in mice via inhibition of Akt activation. Int J Oncol 39: 1381-1390, 2011.

7. Shi GF and Li Q: Effects of oxymatrine on experimental hepatic fibrosis and its mechanism in vivo. World J Gastroenterol 11: 268-271, 2005.

8. Lu LG, Zeng MD, Mao YM, et al: Oxymatrine therapy for chronic hepatitis B: a randomized double-blind and placebo-controlled multi-center trial. World J Gastroenterol 9: 2480-2483, 2003.

9. Ling Q, Xu X, Wei X, et al: Oxymatrine induces human pancreatic cancer PANC-1 cells apoptosis via regulating expression of $\mathrm{Bcl}-2$ and IAP families, and releasing of cytochrome $c$. J Exp Clin Cancer Res 30: 66, 2011

10. Zhang Y, Liu H, Jin J, Zhu X, Lu L and Jiang H: The role of endogenous reactive oxygen species in oxymatrine-induced caspase-3-dependent apoptosis in human melanoma A375 cells. Anticancer Drugs 21: 494-501, 2010.

11. Song G, Luo Q, Qin J, Wang L, Shi Y and Sun C: Effects of oxymatrine on proliferation and apoptosis in human hepatoma cells. Colloids Surf B Biointerfaces 48: 1-5, 2006.

12. Zhang Y, Piao B, Zhang Y, et al: Oxymatrine diminishes the side population and inhibits the expression of $\beta$-catenin in MCF-7 breast cancer cells. Med Oncol 28 (Suppl 1): S99-S107, 2011.

13. Zou J, Ran ZH, Xu Q and Xiao SD: Experimental study of the killing effects of oxymatrine on human colon cancer cell line SW1116. Chin J Dig Dis 6: 15-20, 2005.

14. Song MQ, Zhu JS, Chen JL, et al: Synergistic effect of oxymatrine and angiogenesis inhibitor NM-3 on modulating apoptosis in human gastric cancer cells. World J Gastroenterol 13: 1788-1793, 2007.

15. Baldwin AS: Control of oncogenesis and cancer therapy resistance by the transcription factor NF- $\mathrm{B}$. J Clin Invest 107: 241-246, 2001

16. Aggarwal BB: Nuclear factor- $\kappa \mathrm{B}$ : the enemy within. Cancer Cell 6: 203-208, 2004

17. Carbone $\mathrm{C}$ and Melisi D: NF- $\mathrm{BB}$ as a target for pancreatic cancer therapy. Expert Opin Ther Targets 16 (Supp 2): S1-S10, 2012.

18. North S, Moenner M and Bikfalvi A: Recent developments in the regulation of the angiogenic switch by cellular stress factors in tumors. Cancer Lett 218: 1-14, 2005.

19. Han J, Sun M, Cui Y, et al: Kushen flavonoids induce apoptosis in tumor cells by inhibition of NF- $\kappa \mathrm{B}$ activation and multiple receptor tyrosine kinase activities. Phytother Res 21: 262-268, 2007.

20. Wang ZH, Chen $\mathrm{H}$, Guo HC, et al: Enhanced antitumor efficacy by the combination of emodin and gemcitabine against human pancreatic cancer cells via downregulation of the expression of XIAP in vitro and in vivo. Int J Oncol 39: 1123-1131, 2011.

21. Hidalgo M: Pancreatic cancer. N Engl J Med 362: 1605-1617, 2010.

22. Liptay S, Weber CK, Ludwig L, Wagner M, Adler G, and Schmid RM: Mitogenic and antiapoptotic role of constitutive $\mathrm{NF}-\kappa \mathrm{B} / \mathrm{Rel}$ activity in pancreatic cancer. Int $\mathrm{J}$ Cancer 105: 735-746, 2003.

23. Wang W, Abbruzzese JL, Evans DB, Larry L, Cleary KR and Chiao PJ: The nuclear factor $-\kappa \mathrm{B}$ RelA transcription factor is constitutively activated in human pancreatic adenocarcinoma cells. Clin Cancer Res 5: 119-127, 1999.

24. Scartozzi M, Bearzi I,Pierantoni C, et al: Nuclear factor- $\kappa$ B tumor expression predicts response and survival in irinotecan-refractory metastatic colorectal cancer treated with cetuximab-irinotecan therapy. J Clin Oncol 25: 3930-3935, 2007.

25. Nishi T, Shimizu N, Hiramoto M, et al: Spatial redox regulation of a critical cysteine residue of NF- $\kappa \mathrm{B}$ in vivo. J Biol Chem 277: 44548-44556, 2002.

26. Gonzalez-Perez RR, Xu Y, Guo S, Watters A, Zhou W and Leibovich SJ: Leptin upregulates VEGF in breast cancer via canonic and non-canonical signalling pathways and NFKB/HIF-1 $\alpha$ activation. Cell Signal 22: 1350-1362, 2010.

27. Suboj B, Priya PS, Nandini RJ, et al: Nimbolide retards tumor cell migration, invasion, and angiogenesis by downregulating MMP-2/9 expression via inhibiting ERK1/2 and reducing DNA-binding activity of NF- $\kappa \mathrm{B}$ in colon cancer cells. Mol Carcinog 51: 475-490, 2012.

28. Ye Y, Martinez JD, Perez-Polo RJ, Lin Y, Uretsky BF and Birnbaum Y: The role of eNOS, iNOS, and NF- $\kappa$ B in upregulation and activation of cyclooxygenase-2 and infarct size reduction by atorvastatin. Am J Physiol Heart Circ Physiol 295: N343-N351, 2008 . 
29. Ferrara $\mathrm{N}$ and Alitalo K: Clinical applications of angiogenic growth factors and their inhibitors. Nat Med 5: 1359-1364, 1999.

30. Ferrara N: Role of vascular endothelial growth factor in regulation of physiological angiogenesis. Am J Physiol Cell Physiol 280: 1358-1366, 2001.

31. Brawer MK: Quantitative microvessel density. A staging and prognostic marker for human prostatic carcinoma. Cancer 78: 345-349, 1996

32. Hlatky L, Hahnfeldt P and Folkman J: Clinical application of antiangiogenic therapy: microvessel density, what it does and doesn't tell us. J Natl Cancer Inst 94: 883-893, 2002.
33. Lassau N, Chebil M, Chami L, Bidault S, Girard E and Roche A: Dynamic contrast-enhanced ultrasonography (DCE-US): a new tool for the early evaluation of antiangiogenic treatment. Target Oncol 5: 53-58, 2010.

34. Claudon M, Cosgrove D, Albrecht T, et al: Guidelines and good clinical practice recommendations for contrast enhanced ultrasound (CEUS) - update 2008. Ultraschall Med 29: $28-44,2008$. 